\section{Challenges in International Development}

Mallory G. Sprague

University of Michigan School of Social Work

\section{The Gambia}

The smallest country in continental Africa, The Gambia hosts dozens of international aid organizations within its 4,361 square miles. One of its oldest partners, Peace Corps, has been operating within The Gambia since 1967, just 6 years after the global organization was founded. Volunteers serve in the Agriculture Education, and Health sectors.

\section{Global Field Agency}

Peace Corps main goals are (1) to help the people of interested countries in meeting their need for trained men and women; (2) to help promote a better understanding of Americans on the part of the peoples served; and (3) to help promote a better understanding of other peoples on the part of Americans.

Where We Fall Short

The average volunteer is an upper-middle class white person, newly graduated from university. The shadow of this description is that they likely have limited experience in the work they will demonstrate; they are not reflective of the diversity of Americans; and while in service travel is discouraged, thereby encouraging a limited view of the country and people about which they are later asked to speak as experts. This question of intention, efficacy, and ethics causes much doubt and dissonance, and was the most reported source of stress for volunteers. Where We Succeed

It is an immersive two-year experience that allows an individual to gain massive amounts of perspective. But perhaps development is happening primarily for volunteers, rather than the host country.

\section{Program Development}

From 2014-2016, I volunteered with Peace Corps The Gambia. During my service, I noticed a lack of mental health resources available in country. I proposed a GIS project aimed at providing training to their Volunteer Support Network. However when I began interviewing current volunteers, nearly everyone attributed their stress to "doubting why we are here in the first place." My project refocused to collecting feedback on the perception of the international aid organ-

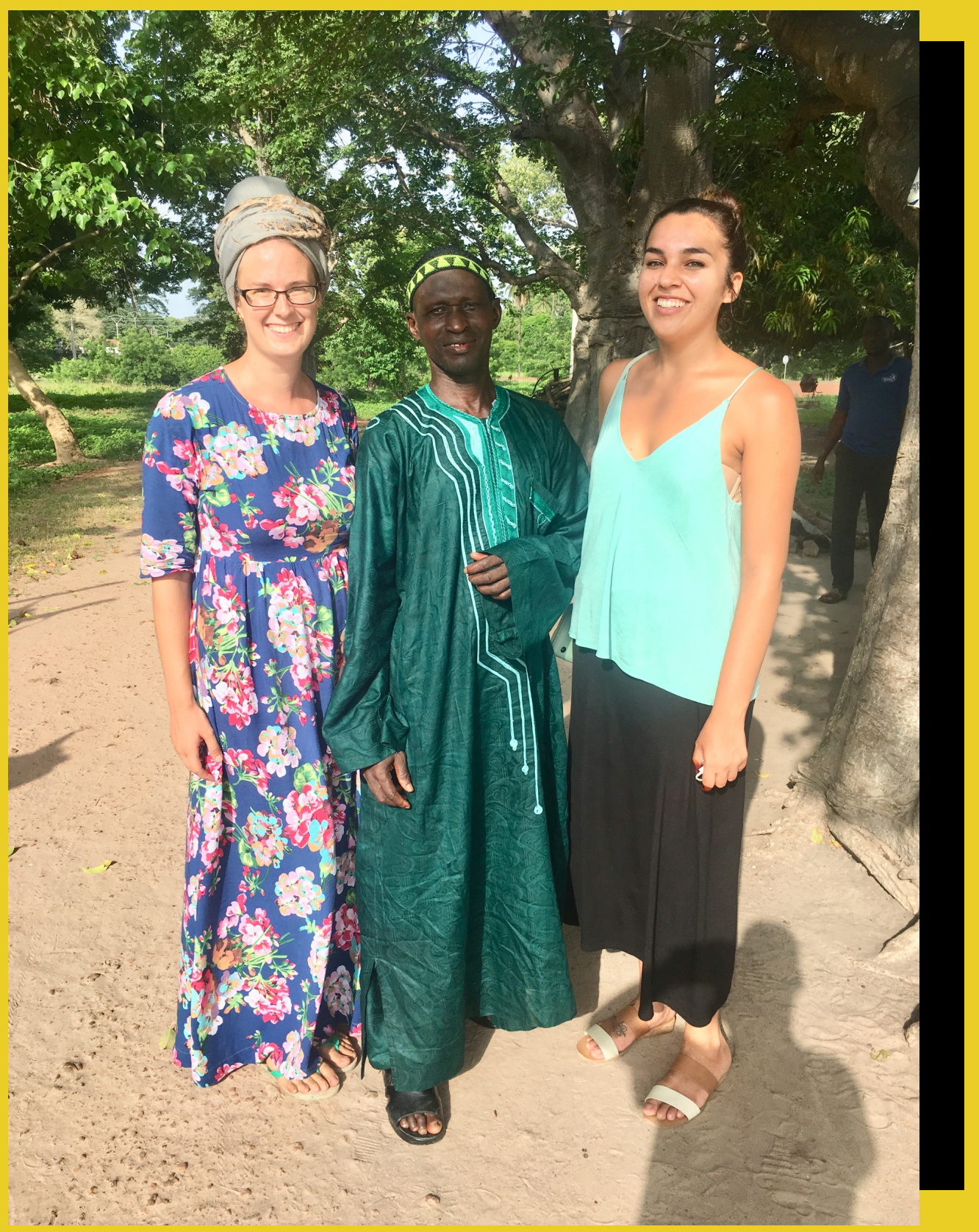
zation as seen by the workers themselves. This was done in collaboration with the preceding volunteer in the village of Geniya, and our shared counterpart, Saikou Nyassi.

What we found was a lot of questions of what makes practice efficacious and ethical. This experience was integral to my future aspirations of practicing interpersonal therapy with diverse populations domestically and abroad.



This poster was created for the Fall 2019 Global Social Work Poster Fair. 